\title{
Medicina regenerativa con células madre adultas
}

\author{
M. Valdés Chavarri ${ }^{a}$, D. Pascual Figal ${ }^{a}$, F. Prósper Cardoso ${ }^{b}$, J. Moreno Montañés ${ }^{b}$, \\ D. García Olmos y y J. A. Barcia Albacar ${ }^{d}$ \\ ${ }^{a}$ Hospital Universitario Virgen de la Arrixaca. Murcia. ${ }^{b}$ Clínica Universitaria de Navarra. Pamplona. \\ ${ }^{c}$ Hospital Universitario La Paz. Madrid. ${ }^{d}$ Hospital General Universitario de Valencia y Centro de Investigación Príncipe Felipe. Valencia
}

En este trabajo se revisa el estado actual de la medicina regenerativa clínica con células madre de adulto en los campos cardiológico, digestivo, corneal y neurológico. Desde el punto de vista cardiológico existe experiencia clínica con progenitores de médula ósea y células de sangre periférica, así como con mioblastos esqueléticos. En el momento actual las células madre del adulto (hematopoyéticas o mesenquimales de médula ósea) constituyen la mejor opción para la regeneración del tejido cardíaco, mostrando los estudios clínicos resultados favorables, sin problemas éticos ni de seguridad. La mayoría de los estudios con mioblastos esqueléticos también han demostrado que contribuyen significativamente a mejorar la función cardíaca, sobre todo la sistólica, aunque tienen el inconveniente no aclarado totalmente, de inducir arritmias ventriculares malignas. Tanto en uno como en otro caso los estudios clínicos están en la fase inicial y se hace necesario nuevos estudios sobre todo randomizados. En el campo digestivo se presenta la experiencia pionera del Hospital La Paz del uso de células madre procedentes de la grasa abdominal en el tratamiento de la patología fistulosa de pacientes con enfermedad de Crohn. En Oftalmología el trasplante de limbo corneal es una práctica reconocida, usándose células del ojo contralateral cuando el daño es en un solo ojo y células de un donante cuando el daño es bilateral. Por último, en el campo neurológico se han identificado diversas zonas del cerebro de mamíferos adultos donde existen células troncales: el hipocampo, la zona subventricular, el bulbo olfatorio y la zona periependimaria de la médula espinal. Por otra parte, es posible obtener neuronas a partir de células troncales adultas procedentes de otros tejidos, como la médula ósea o el tejido adiposo, lo que supondría una fuente prácticamente inagotable de precursores neurales, bien mediante implante directo tras su selección o bien tras su cultivo in vitro. Aunque hasta la fecha la mayor parte de la experimentación es animal, se están poniendo ya en marcha ensayos clínicos de seguridad en esclerosis lateral amiotrófica.

PALABRAS CLAVE: medicina regenerativa, células madre.

Valdés Chavarri M, Pascual Figal D, Prósper Cardoso F, Moreno Montañés J, García Olmos D, Barcia Albacar JA. Medicina regenerativa con células madre adultas. Rev Clin Esp. 2005; 205(11):556-64.
Regenerative medicine with adult stem cells The present state of clinical regenerative medicine with adult stem cells in the cardiology, digestive, corneal and neurological fields are reviewed. From the cardiology point of view, there is clinical experience with bone marrow stem cells and peripheral blood cells and with skeletal myoblasts. At present, the adult stem cells (bone marrow hematopoietics or mesenchymal) constitute the best option for the regeneration of heart tissue, the clinical studies showing favorable results without ethical or safety problems. Most of the studies with skeletal myoblasts have also been demonstrated to significantly contribute to improve heart function, above all, the systolic one. However they have the disadvantage that has not been totally clarified that they induce malignant ventricular arrhythmias. In either case, the clinical studies are in the initial phase and new studies, above all randomized, are necessary. In the digestive field, there is the pioneer experience of the Hospital La Paz on the use of stem cells from abdominal fat in the treatment of fistulous condition of patients with Chron disease. In ophthalmology, the limbal corneal transplant is a recognized practice, using cells from the contralateral eye when the damage is in a single eye and cells from a donor when the damage is bilateral. Finally, in the neurological field, different zones of the adult mammal brain where there are stem cells have been identified: the hippocampus, subventricular zone, olfactory bulb and periependymal zone of the spinal cord. On the other hand, neurons may be obtained from adult stem cells from other tissues, such as the bone marrow or adipose tissue, which means a practically unendable source of neural precursors, either by direct implant after their selection or after their in vitro culture. However, most of the experimentation is animal up to now, clinical trails on safety in amyotrophic lateral sclerosis are now being initiated.

KEY WORDS: regenerative medicine, stem cells.
Correspondencia: M. Valdés Chavarri.

C./ Acisclo Díaz, 2, 14. ${ }^{\mathrm{a}}$

30005 Murcia.

Correo electrónico: vadeschavarri@vadeschavarri.e.telefonica.net

Aceptado para su publicación el 15 de junio de 2005.

\section{Introducción}

Todas las células de nuestro organismo tienen una vida limitada, muriendo y siendo eliminadas tras un determinado tiempo. Paralelamente, las células muertas se 
van sustituyendo por otras, regenerándose a fin de mantener la función de los diferentes órganos y sistemas. Cabría distinguir células "lábiles» de rápida destrucción y regeneración, "estables" de menor destrucción y regeneración y "perennes" de duración prácticamente vital $y$, por tanto, de regeneración casi nula. Se entiende que la pérdida de células lábiles es rápidamente compensada y que no deja secuelas funcionales, mientras que las pérdidas de células estables y perennes, al ser la regeneración deficitaria, ocasionaría trastornos funcionales irreversibles.

Por medicina regenerativa entendemos todas aquellas medidas encaminadas a favorecer la regeneración celular, sobre todo de aquellas enfermedades con muerte y eliminación de células estables y perennes. Si desde el punto de vista celular hemos hablado de células lábiles, estables y perennes, desde el punto de vista regenerativo hablamos de células madre, células capaces de formar uno o varios tipos de células diferenciadas. Aunque se podrían separar por sus características anatómicas y funcionales, diferentes receptores de superficie, factores de transcripción y las diversas proteínas que expresan, en esta breve revisión complicaríamos el tema más que esclarecerlo y por ello es preferible descender a una terminología de uso más común y así hablamos de células madre embrionarias y del adulto, de células totipotenciales, pluripotenciales, multipotenciales y unipotenciales. Las células madre embrionarias son las aisladas en el embrión, mientras que las aisladas en el tejido adulto, postnatales, serían las células madre del adulto. Son embrionarias, las toti y pluripotenciales y son del adulto, las multi y unipotenciales.

Las totipotenciales serían aquellas capaces de formar todas las células diferenciadas del cuerpo y las trofoblásticas de la placenta y tan sólo se encuentran en el embrión, zigoto y las descendientes inmediatas de las dos primeras divisiones celulares. Las pluripotenciales pueden diferenciarse en casi todas las células provenientes de las tres líneas germinales, endodermo, mesodermo y ectodermo, pero son incapaces de generar tejido placentario. Son células embrionarias que forman la masa interna celular del blastocisto, aproximadamente 5 días tras la fertilización. Las multipotenciales son capaces de producir una pequeña proporción de líneas celulares apropiadas a su localización, encontrándose en los tejidos adultos. Algunas, una vez sacadas de su localización habitual, son capaces de transdiferenciarse en células típicas de su nueva relocalización. Las unipotenciales son aquellas con el menor poder de diferenciación, capaces en muchas ocasiones de sólo producir el mismo tipo celular una y otra vez.

No cabe duda de que las células embrionarias son las que tienen la mayor capacidad regenerativa al ser capaces de generar cualquier célula. Sin embargo, y precisamente por su enorme potencialidad, escapan al control y provocan gran cantidad de tumores. Por otra parte hay que tener en cuenta que su obtención supone la muerte inexorable del embrión, es decir, una vida humana en los primeros momentos de su evolución natural, provocando el rechazo de muchos investigadores. Por otra parte, la demostración tanto experimental como en seres humanos de que las cé- lulas postnatales tienen una capacidad regenerativa mucho mayor que la que previamente se pensaba abre un campo impensable hace unos años en el capítulo de la medicina regenerativa, ya que en este caso sería un trasplante antólogo, más fácil de controlar, con menores riesgos y sin los problemas éticos anteriormente delineados.

En la presente revisión se pretende repasar el estado actual de la medicina regenerativa clínica con células madre de adulto en los campos cardiológico, digestivo, corneal y neurológico. En algunos existen ya estudios clínicos con resultados esperanzadores, en otros, como la neurología, los resultados son tan sólo experimentales, pero por su importancia nos ha parecido oportuno incluirlos.

\section{En enfermedades cardíacas}

La pérdida de miocitos ocurre en distintas cardiopatías, como el infarto agudo de miocardio (IAM), la cardiopatía isquémica crónica, la miocarditis y las miocardiopatías. La capacidad que tienen los miocitos adultos de multiplicarse y regenerar el tejido cardíaco dañado es escasa, lo que ocasiona un déficit estructural y funcional permanente que acaba conduciendo a la insuficiencia cardíaca.

Aunque a priori cualquier lesión cardíaca sería tributaria a la terapia celular, el ambiente local ocasionado por el daño agudo en el IAM favorece la diferenciación celular y por ello ha sido la cardiopatía isquémica, preferentemente en su manifestación aguda la que ha despertado un mayor interés, habiéndose demostrado que diferentes tipos celulares mononucleares han sido capaces de regenerar el miocardio necrótico y los vasos dañados. En los últimos 5 años hemos asistido al desarrollo paralelo de una investigación básica, intentando conocer los mecanismos biológicos implicados y de una clínica que ha evaluado de forma entusiasta los resultados iniciales de esta nueva y gran oportunidad de tratamiento.

Los estudios actuales han sido realizados con mioblastos de músculo esquelético, progenitores de medula ósea y células de sangre periférica.

\section{Progenitores de médula ósea y células de sangre periférica}

Las células madre de la medula ósea han demostrado una capacidad ilimitada de proliferación y diferenciación hacia distintos tipos celulares, incluidos los cardiomiocitos. La medula ósea contiene diferentes tipos de células madre, incluidas las hematopoyéticas (CD34+), precursores endoteliales (CD34+CD133+), mesenquimales (CD34-) y progenitores multipotentes del adulto $^{1}$. De forma natural se ha podido observar que tras un IAM se produce una movilización de células madre (CD34+) desde la médula ósea a la circulación periférica, con posterior localización en el miocardio dañado ${ }^{2,3}$, aunque dicha movilización es mínima $e$ insuficiente para regenerar la totalidad del tejido necrosado. Sin embargo, la trasdiferenciación en el caso de las células hematopoyéticas no ha sido observada por 
todos los autores y existen resultados discordantes ${ }^{4 \cdot 6}$. Asimismo, parece que la transformación hacia miocitos es debida en parte a un fenómeno de fusión celular que acompañaría al fenómeno de transdiferenciación celular $^{7}$. En todo caso esta diferenciación requiere de una compleja serie de señales múltiples (célula-célula, citocinas, moléculas de adhesión y factores estimulantes de colonias) que en el momento actual son poco conocidas. Asimismo, existe una intensa investigación sobre qué marcadores de superficie identifican a aquellos tipos celulares con una mayor capacidad para regenerar el miocardio ${ }^{8}$.

En el propio tejido cardíaco existen también células madre multipotenciales. En los últimos años varios trabajos han mostrado la existencia de un ciclo en los propios miocitos ventriculares, tanto en tejido normal como patológico ${ }^{9}$, y se han identificado células cardíacas multipotentes que dan lugar a células endoteliales, musculares lisas y miocitos ${ }^{2}$. Sin embargo, se desconoce por qué estas células son incapaces de regenerar el daño ocasionado por un infarto. Serán necesarios nuevos trabajos que aborden este tipo celular como posible terapia de regeneración.

Vías de administración

El éxito de la terapia podría residir en alcanzar elevadas concentraciones celulares en la zona dañada. Los estudios realizados han usado distintas rutas de administración. La administración intracoronaria se ha utilizado en la fase aguda del IAM. La intramiocárdica requiere de cirugía abierta asociada, y si bien permite una mejor visualización anatómica de la zona, tiene un mayor riesgo de arritmias y en la propia operación. La transendocárdica se realiza percutáneamente a través de catéter intraventricular y un sistema de mapeo electromagnético. Al inyectar las células a alta presión se corre un mayor riesgo de deterioro de las células infundidas y de inducir arritmias. Estas dos últimas vías de administración se han aplicado en pacientes con cardiopatía isquémica crónica, donde el medio es diferente al infarto en fase aguda y de una u otra manera la inyección epi o endocárdica sería el estímulo necesario para la nidación y proliferación celular.

Factores estimulantes

Un enfoque terapéutico alternativo ha sido la potenciación mediante factores estimulantes de colonias, de la movilización fisiológica de células mononucleares de medula ósea hacia la circulación. Si bien en un modelo animal esta estrategia obtuvo resultados favorables ${ }^{10}$, recientemente su evaluación en pacientes con IAM y revascularización percutánea se ha asociado a un aumento de la reestenosis del stent implantado ${ }^{11}$.

Resultados clínicos

En el momento actual disponemos de estudios con escaso número de pacientes y sólo un estudio randomizado, evaluando la seguridad y la efectividad del trasplante de células en la fase aguda del IAM y en la cardiopatía isquémica crónica.

\section{Seguridad}

Los estudios clínicos con células madre de médula ósea o periférica no han informado de arritmias, ni otros efectos adversos como tumores angiogénicos, por lo que no parecen existir problemas de seguridad con este tipo celular. Sólo en algunos estudios en animales se han descrito microinfartos en relación con la inyección intracoronaria de grandes volúmenes, así como la aparición de calcificaciones intramiocárdicas ${ }^{12}$. En un estudio con factor estimulante de colonias, se ha descrito un aumento de reestenosis intrastent ${ }^{11}$, atribuido a la diferenciación hacia células musculares lisas intrastent; sin embargo, en el resto de estudios no se ha descrito este fenómeno.

En el infarto agudo de miocardio

Los estudios realizados han observado a pacientes tras un primer IAM reperfundido con angioplastia primaria y colocación de un stent, infundiendo las células mediante inyección intracoronaria en la arteria responsable del infarto, generalmente en la primera semana tras el IAM. Globalmente todos han demostrado una mejoría de la fracción de expulsión, así como de la perfusión y viabilidad miocárdica, sin observar aumento de la reestenosis, arritmias ni otros eventos adversos significativos.

Strauer et $\mathrm{al}^{13}$ infundió una población de médula ósea (CD133+/CD45+) en pacientes entre 5-9 días tras un primer IAM $(n=10)$, encontrando una reducción significativa del área de necrosis respecto a un grupo control que rechazó la terapia celular. El estudio TOPCARE ${ }^{14}$ evaluó la infusión intracoronaria a los 4,9 $\pm 1,5$ días de un IAM reperfundido, randomizando los pacientes a recibir progenitores de médula ósea (CD34+ CD45+) $(n=29)$ o células mononucleares obtenidas de sangre periférica y cultivadas ex vivo $(\mathrm{CD} 105+\mathrm{CD} 31+)(\mathrm{n}=30)$. A los 4 meses se observó una reducción del tamaño de la necrosis y de los volúmenes ventriculares, así como una mejoría de la fracción de eyección y de la viabilidad miocárdica, persistiendo la mejoría al año. Los resultados fueron similares para ambos grupos celulares. En otro estudio se evaluó el uso de progenitores mononucleares de sangre periférica tras ser movilizados mediante factor estimulante de colonias, encontrando una mejoría en términos de capacidad de ejercicio, función sistólica y perfusión; sin embargo, este estudio fue detenido por un aumento de la reestenosis intrastent atribuida al uso de factor estimulante de colonias ${ }^{11}$. En nuestro país los resultados preliminares del estudio observacional y multicéntrico, TECAM, muestran que la administración intracoronaria de una población celular no seleccionada de médula ósea en pacientes $(n=20)$ tras un primer IAM anterior 10-15 días antes es un procedimiento seguro y tiene como resultado en una mejoría de la función y el remodelado ventricular respecto a una población control contemporánea y no randomizada ${ }^{15,16}$.

Recientemente se ha publicado el primer estudio randomizado ${ }^{17}$, el estudio BOOST, que enfrentó un grupo que recibía $(n=30)$ y un grupo que recibía infusión 
intracoronaria de progenitores de medula ósea 4,8 1,3 días tras el IAM $(n=30)$. A los 6 meses hubo una mejoría significativa de la función sistólica evaluada por resonancia magnética, a expensas de las regiones periinfarto, en el grupo celular, sin cambio significativo de los volúmenes ventriculares.

\section{Cardiopatía isquémica crónica}

Stam et al ${ }^{18}$ evaluaron la inyección intramiocárdica durante cirugía de by-pass en 6 pacientes con un antecedente de IAM entre 10 días y 3 meses antes. Un total de $1,5 \times 10^{6}$ células purificadas de sangre periférica, con el marcador AC133+ (mesenquimales y multipotentes), se inyectaron en la región periinfarto, obteniendo a los 9-16 meses una mejoría funcional de la fracción de eyección del ventrículo izquierdo (FEVI) y la perfusión. En otro estudio se evaluaron 14 pacientes con disfunción ventricular intensa de origen isquémico, a los que se inyectó una población celular de medula ósea seleccionada (CD34+CD45+) de forma transendocárdica mediante un sistema de catéter guiado ${ }^{19}$. A los 2 meses se encontró una mejoría de la perfusión y función ventricular global. Otro trabajo similar, pero en pacientes con angina refractaria $(n=8)$, mostró una mejoría sintomática y de la contractilidad segmentaria a los 3 meses ${ }^{20}$. Por último, en pacientes con enfermedad coronaria grave no revascularizable, un estudio utilizando también inyección trasendocárdica, pero con una población total de médula ósea, mostró también reducción en síntomas e isquemia inducible por ecocardiografía de estrés ${ }^{21}$.

\section{Conclusiones}

En el momento actual las células madre del adulto (hematopoyéticas o mesenquimales de médula ósea) constituyen la mejor opción para la regeneración del tejido cardíaco, mostrando los estudios clínicos resultados favorables, sin problemas de seguridad ni éticos. Sin embargo, nos encontramos aún en una fase inicial de su desarrollo como terapéutica y nuestros esfuerzos deben dirigirse en los próximos años a lograr un adecuado conocimiento del campo de aplicación, las poblaciones celulares más adecuadas y los mecanismos implicados. Para ello será necesario no sólo la potenciación de la investigación básica, sino también el desarrollo de ensayos clínicos con poblaciones amplias.

\section{Mioblastos esqueléticos}

La fuente de células madre con la que más experiencia se tiene en el campo de la regeneración cardíaca, tanto desde el punto de vista experimental como en pacientes, son los mioblastos esqueléticos. Existen numerosas razones por la cuales las células satélite o mioblastos han sido el primer tipo de células madre en ser utilizado con el objetivo de regenerar el miocardio: su capacidad proliferativa in vitro junto al hecho de tratarse de células con un programa de desarrollo limitado a tejido muscular y, por tanto, con mínimas probabilidades de desarrollar tumores, la posibilidad de obtener células autólogas y su gran resistencia a la isquemia ${ }^{22}$. Existen numerosos estudios experimentales utilizando mioblastos esqueléticos en modelos de infarto agudo y crónico en roedores, en animales de mayor tamaño como cerdos u ovejas e incluso en pacientes que han permitido establecer una serie de conclusiones: los mioblastos esqueléticos implantados en un corazón infartado son capaces de injertar tanto en la zona del infarto como alrededor del infarto y diferenciarse en miotubos multinucleados y sobrevivir durante períodos de al menos 18 meses. Sin embargo, el porcentaje de células capaces de injertar en el miocardio, incluso pocas semanas tras el implante celular, es extremadamente bajo, oscilando entre un $1 \%$ y un $6 \%$ de las células implantadas ${ }^{23}$. La mayoría de los estudios también han demostrado que el trasplante de mioblastos contribuye significativamente a mejorar la función cardíaca, mejorando principalmente la función sistólica (fracción de eyección), pero en algunos casos también la función diastólica. En general, los estudios publicados sugieren que la mejoría de la función es proporcional al número de mioblastos injertados ${ }^{24,25}$ y esta mejoría se mantiene en el tiempo. Aunque algunos de los estudios iniciales sugerían que los mioblastos esqueléticos eran capaces de adquirir propiedades similares a las del músculo cardíaco e incluso transdiferenciarse y establecer conexiones electromecánicas ${ }^{26}$, en la actualidad las evidencias indican que no se produce una transdiferenciación de los mioblastos y que además las fibras musculares esqueléticas no son capaces de acoplarse mecánicamente con el resto de los cardiomiocitos ni establecer uniones densas ${ }^{27}$. Sin embargo, también parece claro que las fibras musculares esqueléticas son capaces de adquirir ciertas características de células musculares cardíacas y expresar fibras musculares de contracción lenta y rápida, favoreciendo su resistencia a la fatiga muscular.

Hasta el momento se han publicado 5 estudios clínicos fase 1 con mioblastos esqueléticos autólogos en pacientes con patología cardíaca. Los resultados obtenidos con el primer paciente tratado mediante la administración intracardíaca directa de mioblastos fueron publicados por el grupo de Philippe Menasche ${ }^{28}$, que posteriormente describió los resultados obtenidos en un ensayo fase 1 con un total de 10 enfermos ${ }^{29}$. En este ensayo se incluyeron pacientes con una historia de infarto de miocardio e indicación de cirugía de revascularización coronaria. En el momento de la cirugía se realizó la inyección directa intramiocárdica de mioblastos esqueléticos previamente obtenidos del propio paciente y cultivados in vitro durante 14-16 días. Los resultados de este estudio muestran que el tratamiento mediante la revascularización junto al trasplante de mioblastos se asoció a una mejoría significativa de la función miocárdica (mejoría del engrosamiento sistólico y aumento de la fracción de eyección) junto con signos evidentes, mediante tomografía por emisión de positrones (PET), de aumento de viabilidad miocárdica. Desde el punto de vista de los efectos secundarios el hallazgo más significativo fue 
la presencia de una alta incidencia de arritmias ventriculares que requirieron en 4 pacientes la implantación de un desfibrilador ventricular.

Bien en forma de resumen (estudios fase 1 del grupo de Dib con dosis escaladas de mioblastos y del grupo de Siminiak) ${ }^{30}$ o de artículos ${ }^{23,31-32}$ se han publicado los resultados de 6 estudios de regeneración cardíaca con mioblastos esqueléticos. Estos estudios se han desarrollado en tres situaciones clínicas distintas: administración intramiocárdica en asociación a cirugía de revascularización aortocoronaria ${ }^{29-31}$, por vía percutánea mediante administración endocavitaria ${ }^{32} \mathrm{O}$ de forma adyuvante a la implantación de un sistema de asistencia ventricular ${ }^{23}$. Estos estudios confirman algunos de los hallazgos descritos en modelos experimentales y demuestran la factibilidad del procedimiento. Al menos en dos de los estudios se demuestra anatomopatológicamente que los mioblastos esqueléticos son capaces de injertar en el corazón ${ }^{23,33}$. Por otra parte, es una constante de todos los trabajos que se produce una mejoría funcional con un incremento de la fracción de eyección ventricular. Sin embargo, debido a que en la mayor parte de los estudios el tratamiento con células se asocia a la cirugía de revascularización, en estos momentos es imposible determinar si el trasplante de mioblastos contribuye de forma directa a mejorar la función. En cualquier caso solamente la realización de estudios aleatorizados con y sin administración de mioblastos junto a la cirugía de revascularización permitirán determinar de forma definitiva la eficacia de esta estrategia terapéutica. Al menos 3 estudios aleatorizados están en marcha en Francia, España y EE.UU. La administración percutánea también permitiría determinar la eficacia del tratamiento con mioblastos como sugiere el único estudio publicado hasta el momento ${ }^{32}$. Uno de los aspectos más controvertidos de la utilización de mioblastos, de hecho no anticipado por los estudios experimentales, ha sido la aparición de arritmias cardíacas ${ }^{23,29}$. Aunque existen diversas hipótesis, se desconoce el mecanismo por el cual se producirían estas arritmias, y de hecho la presencia de arritmias no ha sido un fenómeno constante en todos los estudios $^{31}$. Aunque es un aspecto relevante, en estos momentos no se puede afirmar que el trasplante de mioblastos induzca arritmias cardíacas. Los resultados de los nuevos estudios clínicos y experimentales deberán determinar si los mioblastos son arritmogénicos y su posible mecanismo.

\section{En enfermedades corneales}

La fuente de células del epitelio corneal son las células madre que se encuentran en la región del limbo corneal. Estas células, que se encuentran en la zona de transición entre la córnea y la esclera, tienen todas las características de las células madre, ya que poseen una gran capacidad de renovación, que se mantiene a lo largo de la vida, y son capaces de originar células hijas que pueden sufrir un proceso de diferenciación terminal a células especializadas ${ }^{34}$. Sin embargo, no se ha podido demostrar que estas células sean plu- ripotentes, y parece que sólo dan lugar a células del epitelio corneal y conjuntival. Actualmente no existe un marcador biológico definitivo de las células madre del limbo corneal, aunque se han propuesto varios, como la alfaenolasa y más recientemente el factor de transcripción p63, aunque ciertamente estos antígenos pueden aparecer en otras células ${ }^{35}$.

En condiciones fisiológicas las células madre del limbo corneal son capaces de suplir la necesidad de renovación de la córnea. Sin embargo, en algunas situaciones patológicas, como traumatismos, quemaduras, sustancias químicas, sindrome de Stevens Johnson o penfigoide ocular, la capacidad de regeneración de las células limbocorneales se ve desbordada (o se produce una disminución o ausencia de éstas) y se origina un daño corneal permanente ${ }^{36}$. Aunque el trasplante de córnea es una opción, no es eficaz en los casos donde es necesario restaurar el epitelio corneal. Kenyon y Tseng en 1989 fueron los primeros en llevar a cabo un autotrasplante de limbo conjuntival ${ }^{37}$. Posteriormente, tras el conocimiento de las células madre corneales, Kinoshita modificó la técnica para trasplantar células madre del limbo corneal en conejos.

Actualmente el trasplante de limbo corneal es una práctica reconocida, usándose células del ojo contralateral cuando el daño es en un solo ojo y células de un donante cuando el daño es bilateral. Se pueden usar células histocompatibles de un donante vivo o células no compatibles de donantes cadáver. La posibilidad de expandir ex vivo estas células puede reducir el riesgo de deficiencia de células del limbo del ojo sano o del donante ${ }^{38}$. La combinación de células del limbo con membrana amniótica se usa con éxito para promover una rápida reepitelización de la cornea. En España al menos 2 grupos de investigación (Vall d'Hebron y Clínica Universitaria) han implantado células madre limbocorneales con éxito en pacientes con insuficiencia limbocorneal completa, con el resultado de una reepitelización de la córnea con mejoría de la agudeza visual de los pacientes.

\section{En enfermedades digestivas}

Los primeros indicios de que el uso de células madre pudiera ser beneficioso en pacientes con enfermedad inflamatoria intestinal se obtuvieron a finales de la década de los noventa al observar, en algunos casos mejorias sustanciales de los pacientes tras recibir un trasplante de médula ósea. Desde entonces se han publicado casos aislados de tratamiento de brotes de enfermedad de Crohn y de colitis ulcerosa utilizando progenitores hematopoyéticos mediante la tecnología estándar del TMO (trasplante de médula ósea), tanto de forma autóloga como alogénica, pero no hay evidencias firmes sobre la utilidad real de su uso ${ }^{39-41}$. Se ha concluido que es necesario emprender ensayos clínicos aleatorizados y controlados para poder dar pautas adecuadas. A pesar de ello estas experiencias han servido para señalar algunos de los posibles efectos beneficiosos de las células troncales.

Uno de los problemas que más reduce la calidad de vida de los pacientes con enfermedad de Crohn es la 
patología fistulosa $(\mathrm{PF})$, que suele ser compleja y muy resistente a los tratamientos empleados hasta ahora. El tratamiento quirúrgico de la PF ha sido quizás el que más cambios de enfoque ha sufrido en los últimos años. En la década de los ochenta se popularizó la idea de que las fístulas perianales en la enfermedad de Crohn no deberían tratarse quirúrgicamente, condenando a los pacientes a estados de supuración crónica, interviniendo sólo para el drenaje de abscesos y desbridamiento de cavidades. Sin embargo, las corrientes que mantuvieron una actitud intervencionista sobre la PF, junto con un adecuado tratamiento médico de la enfermedad, han comunicado mejores resultados, especialmente en lo que a calidad de vida se refiere. También se están proponiendo nuevos procedimientos quirúrgicos dirigidos a obturar los trayectos con la ayuda de los modernos selladores biológicos basados en los adhesivos de fibrina. En la actualidad la gran mayoría de los cirujanos colorrectales recomiendan que una vez controlado médicamente el brote agudo se realice un tratamiento correcto de los trayectos fistulosos, pero con mayor énfasis en el uso de procedimientos de drenaje basados en sedales (setones), aunque los pacientes frecuentemente quedan con fístulas bien drenadas pero permanentes, lo que disminuye en mucho su calidad de vida. Esta situación es especialmente grave si tenemos en cuenta que frecuentemente se trata de pacientes jóvenes y que cuando son mujeres se dan con mucha frecuencia las fístulas rectovaginales. Estos hechos justifican la investigación con nuevas terapias que puedan mejorar las condiciones locales hasta lograr la correcta cicatrización de los trayectos fistulosos.

Nuestro grupo de trabajo del Hospital Universitario La Paz inició en mayo del año 2002 un ensayo de factibilidad y seguridad (ensayo clínico en fase 1) sobre el uso del trasplante autólogo de células madre procedentes de la grasa en el tratamiento de la PF anorrectal en pacientes con enfermedad de Crohn, cuyos últimos resultados de seguimiento se recogieron en mayo de 2004. Se practicaron ocho procedimientos en 5 pacientes, pudiendo concluir: 1) de los lipoaspirados podemos obtener un suficiente número de células con características citogenéticas de células madre; 2) estas células se reproducen bien en cultivo y entre 5 y 7 días se obtiene una cantidad clínicamente utilizable; 3) la inyección celular no produjo en ningún momento fenómenos de rechazo; 4) en ningún momento a lo largo del seguimiento se han detectado fenómenos de crecimiento celular incontrolado que supongan riesgo tumoral; 5) en 6 de los 8 casos tratados se logró el cierre completo $(75 \%)$ y en dos hubo una clara disminución del flujo; los mayores efectos reparadores de esta terapia se han observado al cabo de 4-8 semanas de la inyección, y 6) ciertos efectos beneficiosos parecen debidos a la demostrada capacidad antiinflamatoria de estas células troncales ${ }^{42,43}$.

A partir de estos datos de factibilidad y seguridad nos hemos planteado la posibilidad de influir sobre los procesos de cicatrización eligiendo la fístula perianal como uno de los exponentes claros del fracaso en la cicatrización. La fístula perianal se define como la comunicación anormal entre el canal anal y la piel perianal. El tratamiento clásico es la intervención quirúrgica, aunque presenta un postoperatorio muy molesto y está gravada por dos importantes complicaciones, la incontinencia anal y la recidiva, lo que justifica la investigación con nuevas modalidades terapéuticas, optando nosotros por el tratamiento del orificio interno y de los trayectos fistulosos con células madre derivadas de lipoaspirados. Nosotros en la actualidad estamos desarrollando un ensayo clínico en fase 2 dirigido a conocer la eficacia y seguridad para el cierre de las fístulas perianales mediante el tratamiento del orificio interno y de los trayectos fistulosos con células madre derivadas de lipoaspirados. El ensayo ha sido aprobado por la Agencia Española del Medicamento en agosto de 2004 y lleva incluyendo pacientes desde septiembre.

\section{Regeneración neurológica}

La terapia celular quizá tenga una importancia especial en neurología dado que hasta ahora se pensaba que las neuronas adultas no se dividian ni se reparaban. Este dogma, junto con el de que "la regeneración axonal en el sistema nervioso central (SNC), es abortiva, dando lugar a la pérdida permanente de las funciones» ${ }^{44}$ hacían que una lesión cerebral fuese irreparable. No hay que olvidar que esta situación se aplica a enfermedades muy prevalentes y con gran impacto social, como el accidente cerebrovascular, la lesión cerebral y medular postraumática, o las enfermedades neurodegenerativas, para las que no existe actualmente alternativa de tratamiento curativo. El aparente fracaso del uso de injertos de células diferenciadas con capacidad de liberar neurotransmisores, fundamentalmente de mesencéfalo fetal en la enfermedad de Parkinson (EP) ${ }^{45}$, ha renovado el interés de la investigación con células troncales neurales (CTN).

Aunque no existe evidencia para asegurar que la terapia celular con CTN es superior al uso de neuronas primarias en injertos fetales, su uso puede permitir la disponibilidad de un número elevado de células en distintos grados de diferenciación, y su manipulación in vitro, ambiental o genética, para mejorar su supervivencia, diferenciación, migración e integración ${ }^{46}$. Es posible obtener los diversos tipos celulares del SNC a partir de diversos orígenes, entre los que se encuentran lineas celulares totipotenciales o pluripotenciales derivadas de células embrionarias. Sin embargo, su carácter heterólogo, el desconocimiento de las señales apropiadas para diferenciarlas en el fenotipo celular maduro deseado y su alto riesgo para producir teratomas plantean actualmente problemas prácticos en cuanto a su uso.

Lo que es realmente novedoso es que es posible obtener CTN desde tejidos adultos. Se han identificado diversas zonas del cerebro de mamíferos adultos donde existen células troncales: el hipocampo, la zona subventricular (SVZ), el bulbo olfatorio y la zona periependimaria de la médula espinal. No se han en- 
contrado en otras localizaciones como la corteza, los ganglios basales o el cerebelo ${ }^{47}$. Estas células, que han sido caracterizadas en roedores como astrocitos ${ }^{48}$, pueden diferenciarse en neuronas y migrar hacia áreas tan distantes como el bulbo olfatorio en condiciones normales o bien hacia zonas dañadas. Estas mismas células han sido identificadas en muestras de SVZ procedentes de autopsias o resecciones quirúrgicas de humanos adultos ${ }^{49}$. La existencia de CTN en el cerebro humano adulto permite plantear la estrategia clínica de la estimulación de su crecimiento, bien localmente o bien tras su explante y expansión in vitro, para reparar las enfermedades neurales.

Por otra parte, es posible obtener neuronas a partir de células troncales adultas procedentes de otros teji$\operatorname{dos}^{50}$, como la médula ósea o el tejido adiposo, los cuales supondrían una fuente prácticamente inagotable de precursores neurales, bien mediante implante directo tras su selección o bien tras su cultivo in vitro. Hasta ahora esta capacidad de transdiferenciación sólo ha sido comprobada in vitro. Existen experimentos que sugieren que es posible que esto se de in vivo, es decir, que tras la inyección en animales de células troncales procedentes de la médula ósea ${ }^{51}$ se encuentren células con el fenotipo del huésped portadoras de material genético del donante ${ }^{52}$. Sin embargo, existen explicaciones alternativas para este fenómeno, y una de ellas puede ser la fusión celular ${ }^{53}$. Pero los efectos beneficiosos de las CTN, además de la reposición de neuronas perdidas por otras que puedan sobrevivir durante mucho tiempo integradas en los circuitos neurales del huésped, pueden producirse por otros mecanismos, como la liberación de neurotransmisores $\mathrm{u}$ otras sustancias que repongan o modifiquen la actividad neural, la liberación de factores de crecimiento o la estimulación de respuestas regenerativas locales mediadas por la inflamación, sin olvidar que el daño tisular provocado por el hecho mecánico del implante o la reacción inmunológica contra las células puede provocar una interferencia en la actividad neural del huésped.

Las enfermedades neurodegenerativas, como la EP, supondrían una de las primeras aplicaciones de la terapia con CTN. La tecnología actual permite generar un número elevado de neuronas dopaminérgicas en condiciones estandarizadas. Sin embargo, estos cultivos dan lugar a mezclas de poblaciones neurales, no siendo posible actualmente una selección adecuada de estas células, por no disponer de antígenos de superficie específicos que permitan su separación por citometría de flujo (FACS) ${ }^{46}$. Hasta ahora casi toda la experiencia de trasplantes de células dopaminérgicas proviene de cultivos de células troncales embrionarias o de células troncales neurales fetales de roedores, primates y seres humanos, existiendo dudas sobre su estabilidad genómica ${ }^{54}$. Los datos sobre su posible alternativa, generar células dopaminérgicas a partir de CTN adultas, son limitados hasta ahora ${ }^{50}$. Por otra parte, es necesario desarrollar nuevas estrategias para mejorar la funcionalidad de los implantes, estimulando la capacidad de éstos para recuperar neuronas dopaminérgicas disfuncionales y promoviendo el creci- miento de los axones desde la sustancia negra hasta el estriado, reconstruyendo el tracto nigroestriatal.

En el caso de la enfermedad de Huntington para que se obtenga un beneficio clínico claro es necesario que se produzca una mayor supervivencia de las células tras su implante. Sin embargo, la terapia celular con CTN se encuentra con dos ventajas adicionales: por un lado, casi todas las neuronas derivadas espontáneamente de CTN son gabaérgicas, apareciendo neuronas con marcadores de interneuronas estriatales tras el implante en el estriado de ratas tanto de células embrionarias de ratón, como de neuroesferas humanas y de células autólogas de médula ósea. Por otra parte, dado que existe regeneración neural espontánea a partir de la SVZ en los pacientes con enfermedad de Huntington, sería posible aumentar la eficacia de la misma ${ }^{55}$.

La esclerosis lateral amiotrófica (ELA) también puede ser un objetivo próximo de la terapia con CTN, inicialmente estimulando su aspecto neuroprotector. El implante intraespinal de neuronas generadas a partir de la línea celular humana NT-2 (teratoma) o la administración intravenosa de células de cordón umbilical humano o de médula ósea retrasa la progresión de un modelo de enfermedad de neurona motora en ratones. Existe un ensayo clínico activo con células procedentes de la médula ósea ${ }^{56}$. En cuanto a la posibilidad de conseguir una neurorreparación con células troncales es más remota, ya que ésta debería sustituir neuronas motoras tanto superiores como inferiores $e$ integrarlas en los circuitos corticales del paciente. Dado que ha sido posible generar células con características colinérgicas a partir de células troncales de diversas fuentes, existe la esperanza de que se puedan aplicar al tratamiento de la ELA ${ }^{57}$.

Otro planteamiento es la reposición celular para regenerar las células mielínicas perdidas en el tratamiento de la esclerosis múltiple. En modelos experimentales de desmielinización por reacción alérgica (encefalomielitis alérgica experimental) o por irradiación se ha demostrado la remielinización de la médula espinal tras la administración local o intravenosa de células procedentes de la médula ósea. Además, células procedentes de neuroesferas derivadas de tejido adulto inyectadas por vía intravenosa o intraventricular son capaces de remielinizar axones desmielinizados $^{58}$

Las enfermedades que cursan con un daño cerebral agudo, tales como el accidente cerebrovascular (ACVA) o las lesiones postraumáticas, suponen un problema más complejo, ya que en ellas no se pierde un tipo celular único, sino un tejido complejo formado por diversos tipos neuronales formando redes, junto con células gliales y vasos. Para reconstruir el tejido cerebral perdido será necesario probablemente el uso de construcciones complejas, quizá soportadas con estructuras de materiales biocompatibles. Entre los distintos tipos de ACVA, el más estudiado ha sido el ictus en los ganglios basales, ya que se ha demostrado la generación de nuevas neuronas a partir de CTN en la SVZ modelos de isquemia focal. A pesar de que no se conoce la funcionalidad de neuronas, éstas expre- 
san marcadores de interneuronas estriatales. Desgraciadamente, más del $80 \%$ de las neuronas mueren durante las primeras semanas tras el ictus, siendo sólo capaces de reemplazar una ínfima fracción de las neuronas que mueren. Sin embargo, si se identifican los estímulos apropiados quizá sería posible provocar la formación de nuevas neuronas a partir de las CTN del adulto. Por ejemplo, en un modelo de isquemia cerebral global la infusión intraventricular de FGF-2 y de EGF se sigue de la regeneración de neuronas piramidales en el hipocampo, cerca del ventrículo. En estos mismos modelos la inyección de CTN procedentes de la médula ósea o del cordón umbilical de diversas especies, incluyendo la humana, contribuye a la repoblación neuronal de regiones cerebrales isquémicas ${ }^{52}$. Sin embargo, la mejoría funcional que se registra en los animales aparece mucho antes de lo que cabría esperar si estas células tuviesen que trasformarse en neuronas, emitir prolongaciones y formar conexiones funcionales apropiadas, por lo que su papel podría consistir en estimular la regeneración a partir de células precursoras locales o bien a través de la fusión celular. Otras maniobras terapéuticas que no implican la infusión de células, sino de sustancias vasodilatadoras, por ejemplo, también estimulan la neurogénesis local ${ }^{59}$.

La terapia celular puede tener, además, otras aplicaciones clínicas en neurología. Las células pueden ser usadas como fuentes o como vectores de fármacos y neurotransmisores hacia diversas dianas del sistema nervioso central. La secreción de estos factores puede conseguirse seleccionando el fenotipo celular adecuado, incluyendo el fármaco en su citoplasma, o bien implantando el gen apropiado en la célula. Una de sus posibles aplicaciones es el tratamiento de enfermedades neurológicas farmacorresistentes focales, como es el caso de la epilepsia ${ }^{60}$ o la EP ${ }^{61}$. Por otra parte, la afinidad que presentan las células madre por las células tumorales ${ }^{51}$ puede aprovecharse como vectores de quimioterápicos o en la preparación de vacunas antitumorales.

\section{BIBLIOGRAFÍA}

1. Weissman IL. Stem cells: units of development, units of regeneration and units in evolution. Cell. 2000;100:157-68.

2. Beltrami AP, Urbanek K, Kajstura J. Evidence that human cardiac myocites divide after myocardial infarction. N Engl J Med. 2001;344:1750-7. 3. Shintani S, Murohara T, Ikeda H. Mobilization of endothelial progenitor cells in patients with acute myocardial infarction. Circulation. 2001;103: 2776-9.

4. Orlic D, Kajstura J, Chimenti S, Jakoniuk I, Anderson SM, Li B, et al. Bone marrow cells regenerate infarcted myocardium. Nature. 2001;410(6829):701-5. 5. Balsam LB, Wagers AJ, Christensen JL, Kofidis T, Weissman IL, Robbins RC. Haematopoietic stem cells adopt mature haematopoietic fates in ischaemic myocardium. Nature. 2004;428(6983):668-73.

6. Murry CE, Soonpaa MH, Reinecke H, Nakajima H, Nakajima HO, Rubart $\mathrm{M}$, et al. Haematopoietic stem cells do not transdifferentiate into cardiac myocytes in myocardial infarcts. Nature. 2004;428(6983):664-8.

7. Zhang S, Wang D, Estrov Z, Raj S, Willerson JT, Yeh ET. Both cell fusion and transdifferentiation account for the transformation of human peripheral blood CD34-positive cells into cardiomyocytes in vivo. Circulation. 2004;110(25):3803-7.

8. Yoon YS, Wecker A, Heyd L, Park JS, Tkebuchava T, Kusano K, et al. Clonally expanded novel multipotent stem cells from human bone marrow regenerate myocardium after myocardial infarction. J Clin Invest 2005 , 115(2):326-38

9. Beltrami AP, Barlucchi L, Torella D, Baker M, Limana F, Chimenti S, et al. Adult cardiac stem cells are multipotent and support myocardial regeneration. Cell. 2003;19;114(6):763-76.
10. Orlic D, Kajstura J, Chimenti S, Limana F, Jakoniuk I, Quaini F. Mobilized bone marrow cells repair the infarcted heart, improving function and survival. Proc Natl Acad Sci USA. 2001;98:10344-9.

11. Kang HJ, Kim HS, Zhang SY, Park KW, Cho HJ, Koo BK, et al. Effects of intracoronary infusion of peripheral blood stem-cells mobilised with granulocyte-colony stimulating factor on left ventricular systolic function and restenosis after coronary stenting in myocardial infarction: the MAGIC cell randomised clinical trial. Lancet. 2004:363(9411):751-6.

12. Yoon YS, Park JS, Tkebuchava T, Luedeman C, Losordo DW. Unexpected severe calcification after transplantation of bone marrow cells in acute myocardial infarction. Circulation. 2004;109:3154-7.

13. Strauer BE, Brehm M, Zeus T. Repair of infarcted myocardium by autologus intracoronary mononuclear bone marrow cell transplantation in humans. Circulation. 2002;106:1913-8.

14. Schachinger V, Assmus B, Britten MB, Honold J, Lehmann R, Teupe C, et al. Transplantation of progenitor cells and regeneration enhancement in acute myocardial infarction: final one-year results of the TOPCARE-AMI Trial. J Am Coll Cardiol. 2004;44(8):1690-9.

15. Avilés FF, San Román JA, García Frade J, Valdés M, Sánchez A, de la Fuente L, et al. Intracoronary stem cell transplantation in acute myocardial infarction. Rev Esp Cardiol. 2004;57(3):201-8.

16. Fernández-Avilés F, San Román JA, García-Frade J, Fernández ME, Penarrubia MJ, de la Fuente L, et al. Experimental and clinical regenerative capability of human bone marrow cells after myocardial infarction. Circ Res. 2004;95(7):742-8.

17. Wollert KC, Meyer GP, Lotz J, Ringes-Lichtenberg S, Lippolt P, Breidenbach $\mathrm{C}$, et al. Intracoronary autologous bone-marrow cell transfer after myocardial infarction: the BOOST randomised controlled clinical trial. Lancet. 2004;364(9429):141-8

18. Stamm C, Westphal B, Kleine HD, Petzsch M, Kittner C, Klinge H, et al. Autologous bone-marrow stem-cell transplantation for myocardial regeneration. Lancet. 2003;361(9351):45-6.

19. Perin EC, Dohmann HF, Borojevic R, Silva SA, Sousa AL, Mesquita CT, et al. Transendocardial, autologous bone marrow cell transplantation for severe, chronic ischemic heart failure. Circulation. 2003;107(18):2294-302. 20. Tse HF, Kwong YL, Chan JK, Lo G, Ho CL, Lau CP. Angiogenesis in ischaemic myocardium by intramyocardial autologous bone marrow mononuclear cell implantation. Lancet. 2003;361(9351):47-9.

21. Fuchs S, Satler LF, Kornowski R, Okubagzi P, Weisz G, Baffour R, et al. Catheter-ased autologous bone marrow myocardial injection in no-option patients with advanced coronary artery disease: a feasibility study. J Am Coll Cardiol. 2003;41(10):1721-4.

22. Menasche P. Skeletal muscle satellite cell transplantation. Cardiovasc Res. 2003:58(2):351-7.

23. Pagani FD, DerSimonian H, Zawadzka A, Wetzel K, Edge ASB, Jacoby DB, et al. Autologous skeletal myoblasts transplanted to ischemia-damaged myocardium in humans. J Am Coll Cardiol. 2003;41(5):879-88.

24. Taylor DA, Atkins BZ, Hungspreugs P, Jones TR, Reedy MC, Hutcheson KA, et al. Regenerating functional myocardium: improved performance after skeletal myoblast transplantation. Nat Med. 1998;4(8):929-33.

25. Pouzet B, Vilquin JT, Hagege AA, Scorsin M, Messas E, Fiszman M, et al. Factors affecting functional outcome after autologous skeletal myoblast transplantation. Ann Thorac Surg. 2001;71(3):844-50; discussion 850-1.

26. Reinecke H, MacDonald GH, Hauschka SD, Murry CE. Electromechanical coupling between skeletal and cardiac muscle. Implications for infarct repair. J Cell Biol. 2000;149(3):731-40

27. Leobon B, Garcin I, Menasche P, Vilquin JT, Audinat E, Charpak S. Myoblasts transplanted into rat infarcted myocardium are functionally isolated from their host. Proc Natl Acad Sci USA 2003:100(13):7808-11.

28. Menasche P, Hagege AA, Scorsin M, Pouzet B, Desnos M, Duboc D, et al. Myoblast transplantation for heart failure. Lancet. 2001;357(9252): 279-80

29. Menasche P, Hagege AA, Vilquin J-T, Desnos M, Abergel E, Pouzet B, et al. Autologous skeletal myoblast transplantation for severe postinfarction left ventricular dysfunction. J Am Coll Cardiol. 2003;41(7):1078-83.

30. Siminiak T, Fiszer D, Jerzykowska O, Grygielska B, Kalmucki P, Kurpisz M. Percutaneous autologous myoblast transplantation in the treatment of post-infarction myocardial contractility impairment - report on two cases. Kardiol Pol. 2003;59(12):492-501.

31. Herreros J, Prosper F, Pérez A, Gavira JJ, García-Velloso MJ, Barba J, et al. Autologous intramyocardial injection of cultured skeletal muscle-derived stem cells in patients with non-acute myocardial infarction. Eur Heart J. 2003;24(22):2012-20.

32. Smits PC, van Geuns RJ, Poldermans D, Bountioukos M, Onderwater EE Lee $\mathrm{CH}$, et al. Catheter-based intramyocardial injection of autologous skeletal myoblasts as a primary treatment of ischemic heart failure: clinical experience with six-month follow-up. J Am Coll Cardiol. 2003;42(12): 2063-9.

33. Hagege AA, Carrion C, Menasche P, Vilquin JT, Duboc D, Marolleau JP, et al. Viability and differentiation of autologous skeletal myoblast grafts in ischaemic cardiomyopathy. Lancet. 2003;361(9356):491-2

34. Espana EM, Grueterich M, Romano AC, Touhami A, Tseng SC. Idiopathic limbal stem cell deficiency. Ophthalmology. 2002;109(11): 2004-10.

35. Pellegrini G, Dellambra E, Golisano O, Martinelli E, Fantozzi I, Bondanza S, et al. p63 identifies keratinocyte stem cells. Proc Natl Acad Sci USA. 2001;98(6):3156-61.

36. Tseng SC. Significant impact of limbal epithelial stem cells. Indian J Ophthalmol. 2000;48(2):79-81. 


\section{VALDÉS CHAVARRI M, ET AL. MEDICINA REGENERATIVA CON CÉLULAS MADRE ADULTAS}

37. Tseng SC, Prabhasawat P, Barton K, Gray T, Meller D. Amniotic membrane transplantation with or without limbal allografts for corneal surface reconstruction in patients with limbal stem cell deficiency. Arch Ophthalmol. 1998; 116(4):431-41.

38. Tseng SC, Meller D, Anderson DF, Touhami A, Pires RT, Gruterich M et al. Ex vivo preservation and expansion of human limbal epithelial stem cells on amniotic membrane for treating corneal diseases with total limbal stem cell deficiency. Adv Exp Med Biol. 2002:506(Pt B):1323-34.

39. Kreisel W, Potthoff K, Bertz H, Schmitt-Graeff A, Ruf G, Rasenack J, Finke J. Complete remission of Crohn's disease after high-dose cyclophosphamide and autologous stem cell transplantation. Bone Marrow Transplant. 2003;32(3):337-40.

40. Ditschkowski M, Einsele $H$, Schwerdtfeger R, Bunjes D, Trenschel R, Beele DW, et al. Improvement of inflammatory bowel disease after allogeneic stem-cell transplantation. Transplantation. 2003;75(10):1745-7.

41. Burt RK, Traynor A, Oyama Y, Craig R. High-dose immune suppression and autologous hematopoietic stem cell transplantation in refractory Crohn disease. Blood. 2003;101(5):2064-6.

42. García-Olmo D, García-Arranz M, García LG, Cuellar ES, Blanco IF, Prianes LA, et al. Autologous stem cell transplantation for treatment of rectovaginal fistula in perianal Crohn's disease: a new cell-based therapy. Int $J$ Colorectal Dis. 2003;18:451-4.

43. García-Olmo D, García-Olmo MA. The vulture and stem cells. N Engl J Med. 2003;349(15):1480-1.

44. Ramón y Cajal S. Histología del sistema nervioso del hombre y de los vertebrados. Madrid: Imprenta y Librería de Nicolás Moya; 1899.

45. Olanow CW, Goetz CG, Kordower JH, Stoessl AJ, Sossi V, Brin MF, et al. A double-blind controlled trial of bilateral fetal nigral transplantation in Parkinson's disease. Ann Neurol. 2003;54(3):403-14.

46. Lindvall O, Kokaia Z, Martínez-Serrano A. Stem cell therapy for human neurodegenerative disorders-how to make it work. Nat Med. 2004;10 Suppl:S42-50

47. Álvarez-Buylla A, Lim DA. For the long run: maintaining germinal niches in the adult brain. Neuron. 2004;41(5):683-6.

48. Doetsch F, Caille I, Lim DA, García-Verdugo JM, Álvarez-Buylla A Subventricular zone astrocytes are neural stem cells in the adult mammalian brain. Cell. 1999;97(6):703-16.

49. Sanai N, Tramontin AD, Quinones-Hinojosa A, Barbaro NM, Gupta N, Kunwar S, et al. Unique astrocyte ribbon in adult human brain contains neural stem cells but lacks chain migration. Nature. 2004;427(6976): $740-4$
50. Jiang Y, Jahagirdar BN, Reinhardt RL, Schwartz RE, Keene CD, OrtizGonzalez XR, et al. Pluripotency of mesenchymal stem cells derived from adult marrow. Nature. 2002:418(6893):41-9.

51. Aboody KS, Brown A, Rainov NG, Bower KA, Liu S, Yang W, et al From the cover: neural stem cells display extensive tropism for pathology in adult brain: evidence from intracranial gliomas. Proceedings of the National Academy of Sciences of the United States of America. 2000;97(23):12846-51. 52. Zhao LR, Duan WM, Reyes M, Keene CD, Verfaillie CM, Low WC. Human bone marrow stem cells exhibit neural phenotypes and ameliorate neurological deficits after grafting into the ischemic brain of rats. Exp Neurol. 2002;174(1):11-20

53. Âlvarez-Dolado M, Pardal R, García-Verdugo JM, Fike JR, Lee HO, Pfeffer K, et al. Fusion of bone-marrow-derived cells with Purkinje neurons, cardiomyocytes and hepatocytes. Nature. 2003;425(6961):968-73.

54. Draper JS, Smith K, Gokhale P, Moore HD, Maltby E, Johnson J, et al. Recurrent gain of chromosomes $17 \mathrm{q}$ and 12 in cultured human embryonic stem cells. Nat Biotechnol. 2004;22(1):53-4.

55. Gaura V, Bachoud-Levi AC, Ribeiro MJ, Nguyen JP, Frouin V, Baudic S, et al. Striatal neural grafting improves cortical metabolism in Huntington's disease patients. Brain. 2004;127(Pt 1):65-72

56. Mazzini L, Fagioli F, Boccaletti R, Mareschi K, Oliveri G, Olivieri C, et al. Stem cell therapy in amyotrophic lateral sclerosis: a methodological approach in humans. Amyotroph Lateral Scler Other Motor Neuron Disord. 2003;4(3): 158-61.

57. Chen J, Magavi SS, Macklis JD. Neurogenesis of corticospinal motor neurons extending spinal projections in adult mice. Proc Natl Acad Sci USA. 2004;101(46): 16357-62

58. Bonilla S, Alarcón P, Villaverde R, Aparicio P, Silva A, Martínez S. Haematopoietic progenitor cells from adult bone marrow differentiate into cells that express oligodendroglial antigens in the neonatal mouse brain. Eur $\mathrm{J}$ Neurosci. 2002;15(3):575-82.

59. Zhang R, Wang Y, Zhang L, Zhang Z, Tsang W, Lu M, et al. Sildenafil (Viagra) induces neurogenesis and promotes functional recovery after stroke in rats. Stroke. 2002;33(11):2675-80

60. Gernert M, Thompson KW, Loscher W, Tobin AJ. Genetically engineered GABA-producing cells demonstrate anticonvulsant effects and longterm transgene expression when transplanted into the central piriform cortex of rats. Exp Neurol. 2002;176(1):183-92.

61. During MJ, Kaplitt MG, Stern MB, Eidelberg D. Subthalamic GAD gene transfer in Parkinson disease patients who are candidates for deep brain stimulation. Hum Gene Ther. 2001;12(12):1589-91 